\title{
Understanding and Strengthening the Emergency Management and Comprehensive Disaster Reduction in China's Rural Areas: Lessons from Coping with the COVID-19 Epidemic
}

\author{
Feng Kong $1,2, * \mathbb{1}$ and Shao Sun ${ }^{3, * \mathbb{D}}$ \\ 1 College of Humanities and Development Studies, China Agricultural University, Beijing 100083, China \\ 2 Center for Crisis Management Research, Tsinghua University, Beijing 100084, China \\ 3 National Climate Center, China Meteorological Administration, Beijing 100081, China \\ * Correspondence: kongfeng0824@cau.edu.cn (F.K.); sunshao@cma.gov.cn (S.S.)
}

Citation: Kong, F.; Sun, S.

Understanding and Strengthening the Emergency Management and Comprehensive Disaster Reduction in China's Rural Areas: Lessons from Coping with the COVID-19 Epidemic. Sustainability 2021, 13, 3642. https:// doi.org/10.3390/su13073642

Received: 25 February 2021

Accepted: 24 March 2021

Published: 25 March 2021

Publisher's Note: MDPI stays neutral with regard to jurisdictional claims in published maps and institutional affiliations.

Copyright: (c) 2021 by the authors. Licensee MDPI, Basel, Switzerland. This article is an open access article distributed under the terms and conditions of the Creative Commons Attribution (CC BY) license (https:// creativecommons.org/licenses/by/ $4.0 /)$.

\begin{abstract}
Community based bottom-up design is the foundation of national emergency management system. The outbreak of COVID-19 epidemic in early 2020 is a major test of emergency management capability in rural China. This paper first describes the necessity of strengthening the emergency management design in rural areas of China. Then this paper introduces the fundamental role of emergency management design based on bottom-up for the security of rural areas in China, especially in improving the level of comprehensive disaster reduction at the grassroots level, which plays an important role in improving the emergency management ability of China's rural areas. Based on the above analysis, this paper takes the COVID-19 epidemic prevention and control of epidemic in rural areas of China as an example, and find out many problems in China's rural emergency management system, such as the grass-roots government's emergency needs cannot be met, the existing mode of systematic lack, the lack of psychological intervention and so on. Finally, this paper proposes to strengthen the emergency management design in China's rural areas from expanding the scope of emergency management subjects, strengthening the systematic design of rural emergency management system and strengthening the psychological intervention in rural areas.
\end{abstract}

Keywords: COVID-19; emergency management; comprehensive disaster reduction; rural area; integrated disaster risk governance; sustainable development; China

\section{Introduction}

Since the founding of the People's Republic of China in 1949, China's emergency management system has experienced a transformation from disaster prevention and mitigation to resilient governance in the process of historical changes [1-3]. Emergency management presents distinct stage characteristics in the aspects of governance system, governance concept and governance organization [4-6].

Since the implementation of the reform and opening-up policy in 1978, China has continuously strengthened the emergency management design within the existing administrative framework [3,6]. Since the outbreak of SARS in 2003, academia in China began to pay extensive attention to the emergency management system [7]. The government also started a new period of research on the design of emergency management system with "one case and three systems" as the core $[2,5,6]$. A complete emergency management system should cover a complete emergency management plan before, during and after the emergency, and have a clear responsibility, unified and standardized emergency management system, mechanism and legal system [4,8,9].

With the increasing frequency and complexity of emergencies, emergency management has become one of the most concerned topics in China [10-13]. Emergency management capacity, as an important aspect of contemporary national governing capacity, requires overall design from the national level, i.e., top-down design is needed [14-17]. 
However, since the emergency management capability of grassroots community and the self-help and mutual aid capability of the community play an important role that cannot be replaced by higher-level governments, emergency management requires not only top-down design from the macro level, but also bottom-up design for grassroots community [18-20].

Since the outbreak of the COVID-19 epidemic, there have been many problems in emergency management in China's rural areas [21]. Therefore, how to understand and strengthen the emergency management and comprehensive disaster reduction in rural areas is one of the important issues in the design of China's emergency management system $[13,21,22]$. In particular, the main body of emergency management in rural areas of China is relatively single [14]. Compared with cities, rural areas have a large area and few people. The emergency management system led by the grassroots government is limited by the shortage of human, material and financial resources $[14,15]$. When facing major disasters such as the COVID-19 epidemic, it cannot effectively carry out emergency response. Due to the lack of attention to the bottom-up design of emergency management for a long time, the emergency management mode in rural areas of China lacks initiative, flexibility and systematicness. In the face of major emergencies, the emergency management in rural areas presents the characteristics of passivity, solidification and fragmentation, which hinder the effectiveness of emergency management. At present, the farmers' cultural level in rural areas of China is generally lower than that in urban areas [15]. In the face of major emergencies, they often lack the ability of self-psychological adjustment. The grassroots government has almost no mechanisms and measures to help farmers carry out psychological adjustment and intervention, which is easy to cause unnecessary panic and even psychological problems. These problems are due to the lack of in-depth understanding of the necessity of emergency management in the long term social and economic development of rural areas in China, and the lack of attention to the bottom-up design of rural emergency management, which leads to greater vulnerability and greater disaster risk in rural areas.

Based on the above problems, this paper puts forward specific measures to solve the problems of emergency management in China's rural areas during the period of prevention and control of the COVID-19 epidemic. This paper first describes the necessity of emergency management in rural areas of China, and expounds the fundamental role of bottom-up design in the practice of emergency management in rural areas of China. As an important part of the bottom-up design of rural emergency management, comprehensive disaster reduction plays a key role in improving the emergency management design in rural areas. This paper expounds the comprehensive disaster reduction work in rural areas. Finally, based on the practice of prevention and control of the COVID-19 epidemic, this paper summarizes the problems in emergency management exposed in rural areas of China, and puts forward corresponding solutions. Among the above contents, the prevention and control measures in rural areas of China during the period of the COVID-19 epidemic reflect the necessity and urgency of the design of emergency management system in rural areas. Many problems in the prevention and control of the COVID-19 epidemic essentially require that the emergency management in rural areas of China must be designed at the bottom-up level. The rapid and effective way to solve these problems is to strengthen the design of comprehensive disaster reduction capacity. The above logic also constitutes the main content framework of this paper (Figure 1). 


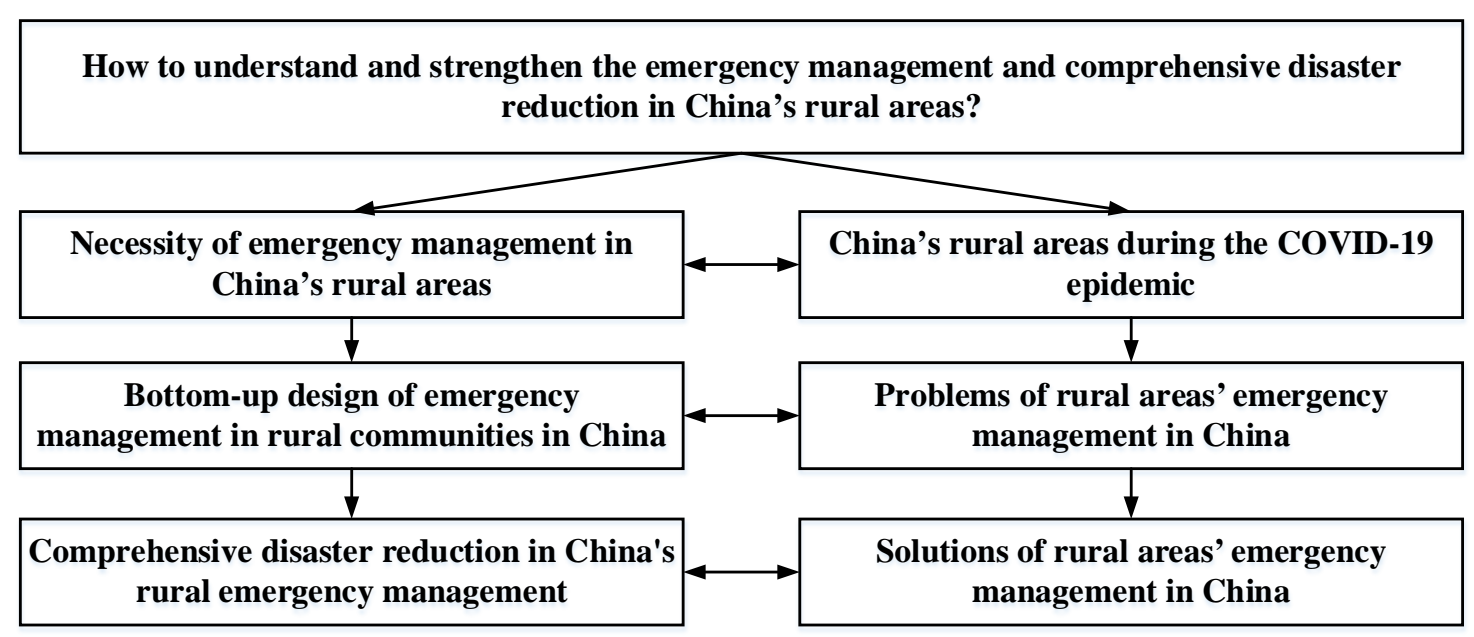

Figure 1. Emergency management and comprehensive disaster reduction in China's rural areas.

\section{Necessity of Emergency Management in China's Rural Areas}

Emergency management in the modern sense was born in western developed countries, marked by the establishment of a special emergency management organization by the government $[18,19,23-26]$. For a long time, China's emergency management design has borrowed the relevant concepts of western developed countries' emergency management and has been improving and innovating in practice $[4,7,27]$. However, China's emergency management are not developed in the same standardized and orderly way as the classical western theories, under the two social contexts of pressure-based system and collectivist culture [1,4]. This difference was clearly presented in the emergency management process in rural areas during the COVID-19 epidemic outbreak [21]. At present, the research on emergency management in China is still at the stage of theory building and system planning $[1,4,9]$. Most of the academic research on emergency management in China focuses on the central level or mega-cities. Additionally, little research has been done on the relevant problems arising in the process of emergency management in rural areas [10,20]. Emergency management in rural areas run through the whole development process of emergency management in China, which has become a key constraint for the improvement of emergency management in China $[13,21,28,29]$. Therefore, it is important to study and improve the current situation and level of emergency management in rural areas for the design of emergency management in China (Figure 1).

At present, the overall development of urban and rural community emergency management design in China is unbalanced. China's urban emergency management capacity is much stronger than that of rural areas $[10,14]$. Compared with the cities, the infrastructure in rural areas is backward [15]. In the face of emergency response to public emergencies, there is a serious shortage of funds, insufficient scientific and technological support capacity, and lagging behind the construction of talents and professional teams [16]. The backward level of economic development in rural areas of China seriously restricts the development of emergency management [10]. At the same time, because of the lack of employment opportunities, migrant workers, represented by young rural workers, flow to urban areas to work, which leads to the weak strength of disaster prevention and reduction in rural areas [14]. Moreover, the publicity and education of disaster prevention and reduction knowledge in rural areas of China lags behind that in urban areas, lacking disaster prevention and relief knowledge and skills of self-rescue and mutual rescue [7]. In addition, the construction supervision of the Chinese government has not effectively covered the rural areas, the relevant legal system is not perfect, and there is a lack of guiding norms for disaster prevention and mitigation in rural areas [5]. Most of the buildings in rural areas of China are built by farmers themselves. Although the Chinese government has already promulgated some relevant standards and specifications for disaster prevention and miti- 
gation of buildings, there are still great difficulties in implementing the relevant standards for self-built buildings in rural areas [10]. As a result, the emergency management in rural areas of China is far behind that in urban areas.

Under the existing dualistic system of urban and rural areas in China, the governance of rural areas includes two broad dimensions: the universal governance of the countryside by the state and the internal governance of the countryside $[7,13,30]$. Among them, emergency management design in rural areas are part of rural governance, including the top-down design of the central government for rural areas and the bottom-up design that facilitates specific practical operations in rural areas [14,21,31]. Emergency management in rural areas of China requires top-down design, but it cannot be separated from bottom-up design including self-help and mutual aid [7]. Compared with urban areas, rural areas in China are relatively backward in terms of economy, technology and human resources, and it is especially important to strengthen the research on emergency management in the rural areas [32-34]. On the one hand, the emergency management design in rural areas of China is an important factor in promoting stable economic development in rural areas. Natural disasters are frequent in China, and strengthening emergency management design in rural areas is conducive to ensuring stable development of rural economic design [33,35]. On the other hand, the emergency management design in rural areas is an inevitable requirement for the sustainable development of China's rural areas [34]. Due to the low safety awareness of rural communities' residents, imperfect rescue facilities, risk warning mechanisms and other factors, the occurrence of emergencies often cause serious losses [33,35]. Therefore, if rural public emergencies can be properly prevented and handled, economic losses and political risks to the country can be effectively avoided or reduced, and the harmony and stability of rural areas can be guaranteed $[27,28,36]$.

The sudden onslaught and rapid spread of the COVID-19 epidemic in early 2020 has had a significant impact on our public health security and economy, and serious impact on rural areas $[21,33,34]$. For example, the travel of migrant workers to return to the city for work is hindered, some agricultural products are not sold, and spring planting supplies are not available [21,34]. However, at the same time, disasters also hold new development opportunities that can bring about new situations in the governance of rural areas in the short and long term in a sense $[7,12,15]$. Therefore, this paper reflects on the problems of emergency management in rural areas during the COVID-19 epidemic from the perspective of emergency management in rural areas and makes corresponding suggestions in order to provide some useful reference for emergency management in rural areas [21,34].

\section{Fundamental Role of Bottom-Up Design for Emergency Management in Rural Communities in China}

In the contemporary society where risk society is increasingly becoming the most important feature of the times, emergency management require macrolevel planning and design at the national level $[15,24,37-40]$. However, compared to other national management activities, emergency management is even more inseparable from the work of the ramified front-line grassroots communities (Figure 1).

First of all, this is because self-help and mutual aid ability is the most important disaster relief ability, and self-help and mutual aid is the most effective way of post-disaster relief [7]. After a disaster, the first relief provided by the people themselves in the disaster area is of utmost importance. Only those grassroots community members who are in close proximity to the disaster can respond quickly to emergency relief. Many studies on community-based disaster risk management show that education, capacity building and public awareness for disaster reduction can significantly reduce the disaster situation and disaster risk [41-47]. According to statistics, on 28 July 1976, China's Tangshan earthquake with a magnitude of 7.8 caused more than 600,000 people to be buried, accounting for $86 \%$ of the population of Tangshan at that time [7,14,15]. In this disaster, 200,000-300,000 people in the disaster area immediately rescued themselves, 300,000-400,000 people were rescued by neighbors and relatives and only about 10,000 people were rescued by the army sent by the Chinese government [14]. Some major disasters occurred in China in recent years, 
including Wenchuan earthquake, Zhouqu debris flow, Lushan earthquake, Ludian earthquake, Yushu earthquake, etc., due to the traffic interruption caused by the disaster, a large number of external rescue personnel and relief materials were difficult to reach the disaster area quickly, which made it difficult for external aid to play a role in the first time [7]. In particular, compared with urban communities, the road traffic and communication facilities of rural communities in China, especially those in remote mountainous areas, are weaker $[48,49]$. Once a sudden major disaster occurs in these rural communities, it is difficult for external rescue personnel and relief materials to reach the disaster area at the first time [14,15]. Therefore, in this case, the rescue ability of the disaster stricken rural communities organizations and self-help and mutual aid ability of disaster victims are particularly important.

Secondly, the rescue time is the decisive factor in the process of disaster relief, and the first time rescue provided by the grassroots community is the most effective. According to the statistics of the relationship between the survival rate and rescue time, the survival rates of the buried persons in China's Tangshan earthquake in 1976 when they were rescued in different periods after the earthquake were $91 \%$ in $30 \mathrm{~min}, 81 \%$ in 1 day, $36.7 \%$ in 2 days, $33.7 \%$ in 3 days, $19 \%$ in 4 days and $7.4 \%$ in 5 days [7]. The statistical results of the relationship between survival rate and rescue time in 1995 Hanshin earthquake in Japan were $80.5 \%$ in 1 day, $28.5 \%$ in 2 days, $21.85 \%$ in 3 days, $5.9 \%$ in 4 days and $5.8 \%$ in 5 days [7]. In the past major earthquakes all over the world, the rescue within $72 \mathrm{~h}$ is the most effective, and that is commonly known as the rescue golden $72 \mathrm{~h} \mathrm{[14].}$

The above two aspects require to strengthen the rural communities emergency management work, and need to enhance the rural residents' disaster risk awareness and emergency management ability [15]. Therefore, it is urgent to attach great importance to the bottom-up design and specific arrangements of rural communities' emergency management. Through the scientific and perfect bottom-up design to improve the ability of disaster prevention and reduction of rural communities, in order to reduce the occurrence of rural disasters, enhance the ability of disaster resistance and disaster relief of rural communities.

The top-down and bottom-up emergency management designs are two kinds of management methods to deal with emergencies $[7,14,15]$. In the bottom-up emergency management design, most of the decision-making power of emergency response is delegated to the middle and lower level organizations, especially the urban and rural grassroots communities [14]. The top-level organizations are only responsible for the long-term strategy of emergency management design and other related major issues. When different emergency management departments have disputes in the emergency response, they are mainly responsible for their own coordination [7]. The bottom-up design of emergency management is helpful to implement the responsibility of emergency management, which can respond to public emergencies at the first time and effectively reduce the disaster [15]. However, in the face of catastrophe, the bottom-up emergency management design cannot effectively organize disaster relief personnel and plan disaster relief materials. In the topdown emergency management design, most of the decision-making power of emergency management lies in the top-level organizations, which are responsible for the allocation of resources. When there are contradictions between different departments, it is mainly coordinated by the top-level organizations. At present, China's top-down emergency management design is relatively mature, which has played a huge role in the emergency response of Wenchuan earthquake in 2008, Yushu earthquake in 2010 and other catastrophes [7]. However, the top-down emergency management design for rural areas will cost a lot of human, material and financial resources [15]. It will have a further impact on the already underdeveloped economy in rural areas. Compared with small and medium-sized disasters, the frequency of catastrophe is less. For the emergency management in rural areas of China, it is obviously unreasonable to adopt only top-down emergency management in frequent small and medium-sized disasters. Therefore, it is urgent for China's rural areas to strengthen the bottom-up emergency management design on the basis of the existing top-down emergency management design. 


\section{Attach Great Importance to Comprehensive Disaster Reduction in China's Rural Emergency Management}

Strengthening comprehensive disaster reduction is the most economic and effective emergency management means in rural areas of China. Disasters will not only have a great and profound impact on people's lives, but also have a significant impact on the whole country's politics, economy, society and even ideological, cultural, ethical and other aspects $[16,28,33]$. China is one of the countries with the most serious natural disasters in the world, and the disaster situation has become an important national condition of China. China's rural areas are prone to disasters, but also the weak link of disaster prevention and relief. The occurrence of disasters is easy to cause or aggravate poverty. More than $80 \%$ of the casualties and economic losses in China come from rural areas [7]. More than $70 \%$ of the 832 poverty-stricken counties in China are located in the areas vulnerable to rainstorm and flood geological disasters, and the phenomenon of poverty caused by disasters and returning to poverty is prominent [7]. More than $70 \%$ of meteorological disasters in China occur in rural areas, especially in the western region $[7,48,49]$. Therefore, strengthening the rural emergency management should become the top priority of China's emergency management.

In the emergency management life cycle, it is usually divided into four segments: disaster prevention and mitigation, emergency preparedness, emergency response and recovery and reconstruction $[4,5,7,14]$. For a long time, whether in theoretical research or in practical development, the public and the government are most concerned about the emergency response, and disaster prevention and mitigation has not attracted enough attention. Currently, however, the emergency management mode of "early warning and response" cannot meet the requirements of the complexity and uncertainty of contemporary disasters and crises [5]. In this context, disaster prevention and reduction as a basic part of emergency management began to attract attention. Internationally, the International Decade for Natural Disaster Reduction was launched in 1990 [7,14,16,32,33]. As a continuation, the International Strategy for Disaster Reduction was established in 2000, and a series of comprehensive disaster reduction work was launched [7].

In the process of actively responding to and participating in these international disaster reduction activities, China has gradually attached importance to disaster prevention and reduction [15]. The Disaster Reduction Plan of the People's Republic of China, the National Comprehensive Disaster Reduction Plan (2005-2010) and China's Disaster Reduction Action have been issued successively, all of which stipulate the capacity-building of disaster prevention and reduction in China [7]. The National Comprehensive Disaster Reduction Plan (2011-2015) further proposes that disaster prevention and reduction should be included in the national development plan, which means that China has begun to make disaster prevention and reduction a national strategy [14]. The National Comprehensive Disaster Reduction Plan (2016-2020) puts forward two adhere and three transformation strategies [7]. Since then, China's comprehensive disaster prevention and reduction has entered a new stage. The two adhere: adhere to the principle of prevention first and combine prevention, resistance and rescue, and adhere to the unity of normal disaster reduction and abnormal disaster relief. Three transformation: to realize the transformation from focusing on post disaster relief to focusing on pre disaster prevention; to realize the transformation from dealing with a single disaster to comprehensive disaster reduction and to realize the transformation from reducing disaster loss to reducing disaster risk. This concept is based on China's basic national conditions and reflects the top-down design and strategic consideration of the national will.

Compared with cities, the economy, technology and talents of rural areas are relatively backward $[13,48,49]$, so it is very important to choose the most economic emergency management strategy. It is undoubtedly the most economical and effective strategy to enhance the emergency management in rural areas to strengthen the construction of disaster prevention and reduction capacity of village level organizations, reduce the occurrence of disasters and improve the ability to resist disasters. As the first part of the life cycle 
of crisis management, disaster prevention and mitigation has a strong constraint on the effectiveness of the whole crisis management. Compared with the input of emergency preparedness, emergency response and recovery and reconstruction, the input of disaster prevention and mitigation cannot only obtain greater economic benefits, but also reduce the loss and injury of the public and the community. Compared with other links, disaster prevention and mitigation is a long-term and permanent action plan to reduce and eliminate the risk of life or property before the disaster. Disaster prevention and mitigation is not only a basic link, but also a long-term measure. Therefore, disaster prevention and mitigation is more suitable for rural areas, which are relatively backward in economy and technology (Figure 1).

According to the research of National Institute of Building Standards and Disaster Reduction Committee of the United States, every dollar spent in disaster prevention and mitigation will save 4 dollars in disaster relief. The importance of disaster prevention and mitigation has been recognized in the practice and theoretical research of emergency management in various countries. In China, the Decision of the CPC Central Committee on Several Major Issues of Promoting Rural Reform and Development, the Outline of the 14th Five Year Plan for National Economic and Social Development and other important national documents have made arrangements for disaster prevention and mitigation [21].

\section{Major Problems and Solutions for Emergency Management in China's Rural Areas during the COVID-19 Epidemic}

\subsection{Major Problems of Rural Areas' Emergency Management}

The COVID-19 epidemic occurred in China in early 2020 and quickly spread across the country in a very short period of time. Rural areas are the weak link in the prevention and control of the COVID-19 epidemic in China and are the focus of this epidemic prevention and control. On 30 January 2020, the Chinese government specifically issued a notice on further improving the prevention and control of the COVID-19 epidemic in rural areas, explicitly requiring governments at all levels to attach great importance to and improve the prevention and control work of the COVID-19 epidemic in rural areas [21]. Faced with the challenges of wide village areas, many blind angles and the difficulty of manual disinfection, there are many difficulties in carrying out epidemic protection work in rural areas. Whether China can win the battle to prevent and control the COVID-19 epidemic in rural areas is a major test of China's governance system and governance capacity in rural areas. From the perspective of emergency management in China's rural areas during the period of COVID-19 epidemic, there are three main problems exposed in the rural emergency management system (Figure 1).

Firstly, the grassroots government-led single-entity emergency management system cannot meet emergency needs. Most of the rural areas in China are located in a relatively independent and closed environment, and the emergency management ability is low. The single-entity emergency management system led by the grassroots government cannot meet the needs of emergency management. The basic requirement of emergency management is to highlight government actions, but the government is not omnipotent and sometimes there is a risk of failure. The basic means for the grassroots government to respond to emergencies is to formulate and implement public policies, and to manage emergencies by policies, regulations and administrative means. However, policy implementation is a complex process, with various difficulties, obstacles and constraints. Although in many cases, the judicious use of coercive power can enable governments to effectively reduce the coordination costs of collective action for individuals or groups, thereby increasing the speed of action response. However, due to the position of the grassroots government under the hierarchical administrative system and the objective environment in which it is located, the grassroots government often does not work efficiently when responding to emergencies, and the effectiveness of the emergency response can be greatly reduced. Therefore, in response to the COVID-19 epidemic outbreak, it is not enough to rely only on the emergency management of the grassroots government, but also requires the close cooperation of the general public. For example, Baihua Village in Supu Town, Qianxi 
County, Bijie City and Guizhou Province, relied on the close cooperation of the general public to contain the spread of the COVID-19 epidemic. According to the epidemic data released by Guizhou Province on 8 February 2020, the four new confirmed cases in the province on 7 February were all from Baihua Village, and the total number of confirmed cases in the village reached 10. As of 7 February, the cumulative number of confirmed COVID-19 virus infections in Guizhou province was 81, with Baihua village accounting for $12.3 \%$ of the total [21]. The severe COVID-19 epidemic prevention and control situation has brought a significant negative impact to Baihua Village and posed a huge challenge to the emergency management of the grassroots government. In order to win the epidemic prevention and control battle, China's grassroots government began to mobilize a wide range of social forces in rural areas, guide and mobilize the general public to actively participate in the epidemic prevention and control work, which finally led to the effective control of the epidemic. It can be seen that, with the risk society becoming the most important feature of the times [40], emergency management in rural areas cannot only rely on the grassroots government, but the power of villagers and other social organizations cannot be ignored. It has become a major trend for rural emergency management to rely on the coordination of multiple entities.

Secondly, the existing emergency response model for emergency management in rural areas of China is relatively reactive and unsystematic. Emergency management in rural areas is a system project and a dynamic process. Its management object is public emergencies, and its main goal is to prevent and reduce the damage caused by the occurrence of emergencies. In the practice of emergency management, if the government initiates the emergency management response mode just after the occurrence of the emergency, it is easy to cause the disconnection of various aspects such as prevention beforehand and response to the emergency. The poor initial response to this COVID-19 epidemic outbreak has led to the spatially widespread spread of the epidemic at a later stage, making the prevention and control situation very critical. Before all infected persons are identified, isolated and treated, there are a considerable number of infectious sources scattered in the society. Without containment and prevention, the government cannot effectively identify and isolate sources of infection, cut off transmission routes and protect public safety. Therefore, in areas where the epidemic is more serious, sealing cities, roads and villages is the easiest and most effective way to control the spread of the epidemic. However, during the COVID-19 epidemic, some rural areas were only closed to roads but not people. There were many unreasonable phenomena such as cars with foreign license plates could not enter the village but cars with local license plates could enter the village. Cars could not enter the village, but people could enter the village without inspection, thus creating a potential risk to epidemic prevention and control. Since emergency management is a system project, there should be a complete emergency plan, and after the occurrence of an emergency, the emergency plan should be activated quickly and responded to in accordance with a standardized and orderly management mechanism. Many rural areas in China did not take into account the characteristics of the local COVID-19 epidemic and adopted the mode of "road closure for the sake of road closure", which was effective but also caused negative impacts on many aspects of society [21].

Thirdly, ignoring the public psychological intervention during the COVID-19 epidemic prevention and control is an obvious short board in the rural emergency management design. The common emergencies in rural areas of China mainly include natural disasters, production accidents, public health events and community mass safety incidents. The emergency disrupts the normal production and living conditions of rural people. Emergency response and post disaster reconstruction are the focus of work for a period of time. After most emergencies, the focus of public attention is often relief material support. Governments at all levels have repeatedly stressed the need to strengthen the security of rural emergency supplies, increase the investment and management of special funds for rural areas, increase the allocation of monitoring and response equipment and strengthen the reserve and comprehensive management of emergency supplies. However, few people 
pay attention to psychological problems. For example, the 8.0 magnitude Wenchuan earthquake in China in 2008 caused significant economic and property damage in rural areas of Mianyang City, Sichuan Province. At the same time, 75.23\% of rural people felt they had suffered psychological trauma, and more than half of the rural people felt that they needed to receive psychological counseling [7,14,15]. During the COVID-19 epidemic, relevant data released by the Psychological Help Line of Beijing Normal University in 2020 showed that $44 \%$ of the population felt panic, fear and dread; $19 \%$ of the population experienced health anxiety and suspected that they were suffering from COVID-19 epidemic and $4 \%$ of the population had aggravated their original psychological problems as a result of the COVID-19 epidemic outbreak, e.g., anxiety, depression and bipolar disorder [21].

In addition, the social psychology of people in rural areas of China also affected the prevention and control of the epidemic in many aspects during the period of COVID-19 epidemic. For example, the rush to buy household goods caused by mass panic has led to shortage of production and household goods in some rural areas. Some grassroots community control measures do not respect the basic psychological needs of the people and have led to a number of conflict incidents. The two weeks or even longer mandatory quarantine has caused confusion, panic and fear among some rural people [21]. In the process of emergency management in rural areas of China, the focus is often only on socioeconomic development to the neglect of social psychology. However, the layout of post-epidemic psychological reconstruction in rural areas is as important as economic reconstruction. Psychological guidance and reconstruction is also an important element of emergency management design in rural areas.

\subsection{Solutions of Rural Areas' Emergency Management}

Emergency management design is an extremely complex and long-term topic. In response to the above-mentioned problems in the process of emergency management in rural areas of China during the COVID-19 epidemic, the following recommendations were made in this paper with a view to raising the emergency management design in rural areas to a high level (Figure 1).

Firstly, it is urgent to expand the main scope of emergency management design and encourage multiparty participation. The grassroots government plays a very important role in the emergency management design in China's rural areas, but expanding the scope of the subject of emergency management design and encouraging the participation of multiparty is the general trend of emergency management in rural areas. In the contemporary risk society [40], the grassroots government's overzealousness in the emergency management in rural areas will inevitably reduce the space for NGOs to participate in emergency management and the opportunities for civil society organizations to participate, which will in turn lead to a reduction in the opportunities and channels for information exchange between the top and bottom, affecting the government's efficiency and increasing the government's operating costs. China's rural areas are a society of acquaintances, and it is not enough to rely solely on the power of the grassroots government to deal with emergencies, and sometimes it is even counterproductive. People with a history of contact with high outbreak areas during the COVID-19 epidemic prevention and control period are one of the most important ways for the spread of the epidemic. During the extraordinary period of COVID-19 epidemic prevention and control, these individuals with a history of contact with high epidemic outbreak areas become the primary surveillance targets [21]. Although many people in rural areas of China leave their villages to work in urban areas, whether or not a returning person has a history of exposure to high epidemic outbreak areas is a particularly easy piece of information for village cadres and villagers in general to learn. Relying on the general villagers allows for timely and graded prevention and control of epidemics in rural areas. However, only relying on the government, whether it is door-todoor visits or telephone inquiries, the authenticity of the results can hardly be guaranteed, which invariably increases the cost of searching for information by the government. The degree of cooperation of people in rural areas and the involvement of relevant civil society 
organizations in the COVID-19 epidemic are key to the effective control of the epidemic outbreak in rural areas. Mandatory quarantine, crowd avoidance and travel bans in rural areas during the COVID-19 epidemic outbreak were also difficult to enforce through government executive orders. Active self-isolation measures by rural people are more likely to reduce the risk of epidemic transmission than mandatory government measures. Therefore, emergency management in rural areas cannot rely on the government alone, but needs to fully mobilize various forces in the village, especially the close cooperation of the general public, and needs the government to cultivate rural emergency social organizations to supplement the work of the government.

Secondly, it is urgent to strengthen the systematic design of rural emergency management. In recent years, both theoretical research and practical application level design, China's rural emergency management has a certain development, but has not yet formed a systematic. Emergency management requires proactive and comprehensive consideration and appropriate bridging by managers, otherwise it is easy to fall into the governance dilemma of "treating the head when it hurts and treating the foot when it hurts" and fragmented management. During the prevention and control of the COVID-19 epidemic, some rural areas in China were at a loss as to what to do in the face of the sudden epidemic, and some of the prevention and control measures introduced were changed from time to time, and there were even illegal and criminal acts that seriously hindered the prevention and control of the epidemic, causing dissatisfaction among rural people. For example, in the early stage of China's prevention and control of the COVID-19 epidemic, according to the information issued by the General Office of Henan provincial government, on 21 January 2020, Wangwu Town, Jiyuan City, held the COVID-19 epidemic prevention and control meeting [21]. After the meeting, the leaders of Qiaozhuang village in Wangwu town did not timely arrange and deploy the epidemic prevention and control work as required. From 30 January 2020 to 31 January 2020, the epidemic prevention and control steering group of Wangwu town government inspected the epidemic prevention and control work in Qiaozhuang village twice. It was found that there was no epidemic prevention and control measures and plan in the village, and the leaders of Qiaozhuang village could not be contacted at the first time [21]. The epidemic prevention and control steering group of Wangwu town government ordered Qiaozhuang village to take rectification measures. Qiaozhuang village quickly took measures such as the village and roads lockdown, and did not inform the villagers of the specific situation. In a short period of time, the rural migrant workers from the city to return to the village had been seriously affected, and even a conflict occurred. At the same time, the village also violated the regulations and gathered people to hold a birthday party twice in this period [21]. Emergency management is a dynamic process, and the existing emergency response model has been quite passive for some time due to the lack of systematicity, completeness and scientificity of the COVID-19 epidemic prevention and control. The various policies introduced by the government also appeared to be fragmented or overlapping and could not be institutionalized. Therefore, the process of emergency management in rural areas should be coordinated by multiparty in an integrated manner to strengthen and improve the systemic nature of rural emergency management and eradicate fragmented management.

Thirdly, it is urgent to pay attention to the psychological intervention in rural areas during the period of epidemic prevention and control. Psychosocial services are a special type of public service, and the emphasis has always been on post-event material support after an emergency in rural areas, to the neglect of post-event psychological intervention. One of the most obvious differences between urban and rural areas in China is the relatively low overall literacy level in rural areas. The lack of general scientific knowledge of the rural people determines their greater need to receive psychological guidance and reconstruction to get rid of fear. During the prevention and control of the COVID-19 epidemic, there was excessive panic in some rural areas and various road closures were used to physically block and isolate administrative villages from each other in response to the COVID-19 epidemic outbreak. For example, Tunli Town, Yaodu District, Linfen City and Shanxi 
Province has 12 administrative villages with a total population of 20,832 . In the early stage of prevention and control of the epidemic of COVID-19 in 2020, due to the excessive release of information by all kinds of media and the difficulty in distinguishing the true from the false, the villagers in 12 villages of Tunli town were in a panic, and the living materials in the nearby supermarkets were snapped up. Tunli village of Tunli town closed all the roads into the village, which led to the blocking of the physical contact between the village and the outside, which aggravated the panic of the villagers in the short term [21]. Chinese governments at all levels issued a number of official messages through relevant channels. For example, the Ministry of Transport of the People's Republic of China issued an emergency notice on 30 January 2020, requesting that there should be no unauthorized road blocking, in order to ensure the basic smooth passage of highways during the Chinese Spring Festival and maintain normal traffic order. So far, the road closures in rural areas have been restrained. It can be seen that it is difficult for rural people to have a rational and comprehensive cognitive ability for new emergent things or emergencies, which undoubtedly increases the rural people's stress and panic, making them more in need of post-event psychological intervention. Therefore, emergency management in rural areas should pay attention to post-event psychological intervention, make up for the shortcomings of emergency management in rural areas, and protect rural people's psychological health. It is recommended to focus on the following three aspects. The first is to strengthen the promotion and education of mental health in rural areas, especially the promotion of general knowledge of mental health, personal psychological adjustment skills after the event, etc. The second is to strengthen the medical services of family doctors contracted in rural areas, especially focusing on the mental health of rural people. The third is to broaden the channels and coverage of psychological intervention services in rural areas. With the development of information technology, there are many new communication channels and ways to choose for psychological intervention, such as WeChat, Tiktok, QQ, Weibo, online forums, etc. The emergence of these new technologies provides convenience and possibility to broaden the channels and coverage of psychological intervention services in rural areas.

\section{Summary}

In the process of China's urbanization, it is also accompanied by the development of rural areas. Compared with cities, industries and citizens, rural areas, agriculture and farmers are relatively weak, often marginalized to varying degrees, and become the appendages of industrialization and even information society. Therefore, strengthening and improving the governance of rural areas, agriculture and farmers has become an urgent task of the government. During the outbreak of the COVID-19 epidemic, the epidemic situation in China's rural areas is more severe than that in cities. If the epidemic situation in rural areas cannot be effectively prevented and controlled, it will lead to the threat to the life safety and health of the rural people, the failure to restore the order of rural production and life and the failure of a large number of returning people to return to the city in time, which will bring great losses to urban production, life and normal operation. The emergency management system design in rural areas has been related to the effectiveness of national emergency management. Therefore, the government should pay more attention to the problems brought by major public emergencies to rural economic security, agricultural production safety and farmers' personal safety and the emergency management in rural areas deserves our more extensive attention and research.

Author Contributions: All authors contributed equally to this work. All authors wrote, reviewed, and commented on the manuscript. All authors have read and agreed to the published version of the manuscript.

Funding: This research was funded by the National Basic Research Program of China, grant number 2018YFC0806900, 2018YFC1509001, 2019YFC1510202 and 2018YFC1509003, the National Natural 
Science Foundation of China, grant number 41701103, 41775078, 41801064 and 71790611, and the Beijing Social Science Foundation Project, grant number 19JDGLA008.

Institutional Review Board Statement: Not applicable.

Informed Consent Statement: Not applicable.

Data Availability Statement: No new data were created or analyzed in this study. Data sharing is not applicable to this article.

Acknowledgments: The authors would like to acknowledge the helpful comments of two anonymous referees of the journal, who have helped to improve this paper.

Conflicts of Interest: The authors declare that no conflict of interest exists.

\section{References}

1. Zhang, H.; Tong, X. Structural change in China's emergency management: Theoretical generalizations. Chin. Soc. Sci. 2016, 2, 77-98.

2. Zhong, K. One case, three systems: The basic framework of China's emergency management system. Nanjing Soc. Sci. 2009, $11,83-89$.

3. Lv, X.; Han, Z. Emergency management in China: Towards a comprehensive model? J. Risk Res. 2019, 22, 1425-1442.

4. Zhong, K. Evolution and development of China's emergency management institutions: An observation based on coordination perspective. Public Manag. Policy Rev. 2018, 7, 21-36.

5. Xue, L. Evolution of emergency management system in China. Adm. Reform. 2010, 8, 22-24.

6. Lv, X.; Xue, L. Managing the unexpected: Sense-making in the Chinese emergency management system. Public Adm. 2016, 94, 414-429.

7. Shi, P. IHDP/Future Earth-Integrated Risk Governance Project Series: Disaster Risk Science; Springer: Berlin/Heidelberg, Germany, 2019.

8. Jiang, D.; Li, Z. Study on assessment mechanism of emergency management system in China. Adv. Mater. Res. 2011, 2, 403-408. [CrossRef]

9. Kong, F. Understanding China's national emergency command system from the perspective of power and responsibility allocation. Sustainability 2021, 13, 301. [CrossRef]

10. Kong, F.; Wang, Y.; Lv, L.; Meng, Y.; Shi, P. Progress and prospect of the global and complex impact of catastrophe on economy in the context of interconnection. J. Cent. China Nor. Uni. (Nat. Sci. Ed.) 2018, 52, 871-882.

11. Kong, F.; Sun, S. Better understanding the catastrophe risk in interconnection and comprehensive disaster risk defense capability, with special reference to China. Sustainability 2021, 13, 1793. [CrossRef]

12. Kong, F. Better understanding positive and negative impacts of disasters on regional economies, with special reference to China. J. Contingencies Crisis Manag. 2020, 28, 479-481. [CrossRef]

13. Rhee, S. Emergency Management demand and the establishment of the emergency management system in China's rural areas. In Proceedings of the 2012 International Conference on Public Administration (8th), Hyderabad, India, 25-27 October 2012.

14. Shi, P.; Xu, W.; Wang, J. Natural Disaster System in China. Natural Disasters in China; Springer: Berlin/Heidelberg, Germany, 2016.

15. Shi, P.; Jeager, C.; Ye, Q. Integrated Risk Governance; Springer: Berlin/Heidelberg, Germany, 2013.

16. Li, M. Study on Raising Social Fund to Redistribute Disaster Risk with Lottery and Insurance. Ph.D. Thesis, Beijing Normal Universty, Beijing, China, 2016.

17. Liu, Y.; Yin, K.; Chen, L.; Wang, W.; Liu, Y. A community-based disaster risk reduction system in Wanzhou, China. Int. J. Disaster Risk Reduct. 2016, 3, 379-389. [CrossRef]

18. Robin, C.S. Capacity building approaches to emergency management in rural communities: Recommendations from survivors of the British Columbia Wildfires, 2003. Int. J. Emerg. Manag. 2007, 4, 250-268.

19. Ha, K.M. The role of community-based organization in emergency management in rural Korea. Lex Localis 2012, 10, 187-202. [CrossRef]

20. Hu, J.; Chen, C.; Kuai, T. Improvement of emergency management mechanism of public health crisis in rural China: A review article. Iran. J. Public Health 2018, 47, 156-165. [PubMed]

21. State Council of China. Review of the Authoritative Release of the Joint Prevention and Control Mechanism of the State Council. Available online: http:/ / sousuo.gov.cn/column/49276/0.htm (accessed on 12 February 2021).

22. Chen, F.; Guo, H. Disaster Risks and Response Strategies in Process of Urbanization in China. Contributing Paper to GAR; World Economic Forum: Geneva, Switzerland, 2019.

23. Manley, W.G.; Furbee, P.M.; Coben, J.H.; Smyth, S.K.; Summers, D.E.; Althouse, R.C. Realities of disaster preparedness in rural hospitals. Disaster Manag. Response 2006, 4, 80-87. [CrossRef] [PubMed]

24. Manyena, S.; Bernard, S. Rural local authorities and disaster resilience in Zimbabwe. Disaster Preve. Manag. 2006, 15, 810-820. [CrossRef]

25. Assmuth, T.; Mikael, H.; Benighaus, C. Integrated risk assessment and risk governance as socio-political phenomena: A synthetic view of the challenges. Sci. Total Environ. 2010, 408, 3943-3953. [CrossRef] [PubMed] 
26. Syed, T.K.; Apturkar, D.K.; Dandekar, K.N. Emergency management and its effect on clinical profile of fournier's gangrene in patients presenting at a rural setup. Int. Surg. J. 2019, 6, 4397. [CrossRef]

27. Zhang, X.; Yi, L.; Zhao, D. Community-based disaster management: A review of progress in China. Nat. Hazards 2013, 65, 2215-2239. [CrossRef]

28. Tian, L.; Yao, P. Preferences for earthquake insurance in rural China: Factors influencing individuals' willingness to pay. Nat. Haz. 2015, 79, 93-110. [CrossRef]

29. Fan, Y.; Tanoue, K. A study on the process of the planning and construction of hope primary school in rural area of China. J. Archit. Plan. (Trans. AIJ) 2017, 82, 1413-1423. [CrossRef]

30. Loh, B. Disaster risk management in Southeast Asia: A developmental approach. Asian Econ. Bull. 2005, 22, 229-239. [CrossRef]

31. Yang, Y.; Fu, C. Inclusive financial development and multidimensional poverty reduction: An empirical assessment from rural China. Sustainability 2019, 11, 1900. [CrossRef]

32. United Nations International Strategy for Disaster Reduction (UNISDR). Sendai Framework for Disaster Risk Reduction 2015-2030; United Nations: New York, NY, USA, 2015.

33. United Nations International Strategy for Disaster Reduction (UNISDR). Global Assessment Report on Disaster Risk Reduction; United Nations: New York, NY, USA, 2019.

34. World Economic Forum. Global Risk Report 2020, 15th ed.; World Economic Forum: Geneva, Switzerland, 2020.

35. Meng, Y.; Yang, S.; Shi, P.; Eager, C.C. The asymmetric impact of natural disasters on China's bilateral trade. Nat. Haz. Earth Sys. Sci. 2015, 15, 2273-2281. [CrossRef]

36. Sharif, M.; Shu, S. The benefits of emergency reserves: Greater preference and persistence for goals that have slack with a cost. J. Mark. Res. 2017, 54, 495-509. [CrossRef]

37. IPCC SREX. Managing the Risks of Extreme Events and Disasters to Advance Climate Change Adaptation; Cambridge University Press: Cambridge, UK, 2012.

38. IPCC AR5. Intergovernmental Panel on Climate Change 2013 fifth Assessment Report (AR5); Cambridge University Press: Cambridge, UK, 2013.

39. IPCC SR1.5. Global Warming of $1.5^{\circ} \mathrm{C}$ : An IPCC Special Report on the Impacts of Global Warming of $1.5^{\circ} \mathrm{C}$ above Pre-Industrial Levels and Related Global Greenhouse Gas Emission Pathways, in the Context of Strengthening the Global Response to the Threat of Climate Change, Sustainable Development, and Efforts to Eradicate Poverty; Cambridge University Press: Cambridge, UK, 2018.

40. Beck, U.; Ritter, M. Risk society: Towards a new moderniy. Soc. Forces 1992, 73, 432-436.

41. Maskrey, A. Disaster Mitigation: A Community Based Approach; Oxfam GB: London, UK, 1989.

42. Wisner, B.; Lópezcarresi, A.; Fordham, M.; Kelman, I.; Gaillard, J. Disaster Management: International Lessons in Risk Reduction, Response and Recovery; Routledge: London, UK, 2013.

43. Khan, A.N.; Jan, M.A. Community Based Disaster Risk Management in Pakistan; Springer: Berlin/Heidelberg, Germany, 2015.

44. Bajek, R.; Matsuda, Y.; Okada, N. Japan's Jishu-bosai-soshiki community activities: Analysis of its role in participatory community disaster risk management. Nat. Hazards 2008, 44, 281-292. [CrossRef]

45. World Trade Organization. World Trade Report 2012; World Trade Organization: Geneva, Switzerland, 2012.

46. United Nations International Strategy for Disaster Reduction (UNISDR). Living with Risk: A Global Review of Disaster Reduction Initiatives; United Nations: New York, NY, USA, 2004.

47. Kong, F.; Lv, L.; Wang, P.; Yan, X.; Wang, Y. Basic definition and characteristics of disaster defense capability. J. Catastrol. 2018, $33,1-4$.

48. Kong, F. Third discussion on the basic definition and characteristics of disaster defense. J. Catastrol. 2021, 36, 1-9.

49. Kong, F. Re-discussion on the basic definition and characteristics of disaster defense. J. Catastrol. 2020, 35, 6-10. 